\title{
2016 年我国内地寨卡病毒的输入和传播风险评估
}

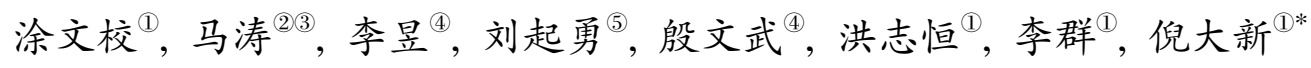 \\ (1) 中国疾病预防控制中心卫生应急中心, 北京 102206; \\ (2) 中国现场流行病学培训项目组, 北京 100050; \\ (3) 南京市疾病预防控制中心, 南京 210003; \\ (4) 中国疾病预防控制中心传染病预防控制处, 北京 102206; \\ (5) 中国疾病预防控制中心传染病预防控制所, 北京 102206 \\ * 联系人, E-mail: nidx@ @ chinacdc.cn
}

2016-03-14 收稿, 2016-03-21 修回, 2016-03-21 接受, 2016-03-29 网络版发表

\begin{abstract}
摘要＼cjkstart寨卡病毒病在全球多地流行, 可致小头畸形、格林-巴利综合征等神经系统疾病. 2016年1 2月我国内地发现 输入性病例10例，未发生本地传播。为明确2016年3 12月该病输入我国内地和传播的风险，根据我国内地登革热输 入和传播规律、人员往来、伊蚊活动、人群密度等资料, 通过定性和定量的风险评估, 本文认为, 我国内地将会继续 发现输入性病例, 如果2016年东南亚不流行, 则预测2016年3 12月我国内地可能发现输入病例为8 68例; 如果东南 亚也出现类似往年登革热一样的流行规模，则预测2016年3 12月我国内地可能发现输入性病例为 106 876例. 6 10 月是发生本地传播最有可能的时间; 广东、云南、海南、福建、广西和浙江等省区是最可能发生本地传播的地区, 其 余有白纹伊蚊的省市可能出现本地传播, 内蒙古、吉林、黑龙江、青海、宁夏、新疆等省区和辽宁、陕西、甘肃、西 藏无伊蚁分布地区, 全年均不会发生本地传播. 建议各地继续做好输入性病例的监测, 有本地传播风险的地区需加 强蚊媒监测和控制, 做好我国内地赴疫区旅行人员的健康提示, 并根据国际疫情和研究进展动态开展风险评估.
\end{abstract}

关键词寨卡病毒病, 风险评估, 蚊媒传染病, 输入病例, 本地传播

寨卡病毒病(Zika virus disease)类似于登革热, 是经伊蚊传播、由寨卡病毒(Zika virus)引起的一种自 限性急性疾病, 通常 2 7 d可自愈. 2015年10月, 巴西 报告新生儿小头畸形明显上升, 时空分布与寨卡病 毒流行区相吻合; 之后有更多证据表明寨卡病毒感 染与小头畸形 ${ }^{[1]}$ 和格林-巴利综合征有关 ${ }^{[2]}$. 2016年2 月 1 日, 世界卫生组织(WHO)宣布巴西聚集性小头畸 形和其他神经系统疾病为 “国际关注的突发公共卫生 事件”, 病因怀疑与寨卡病毒感染有关；2015年1月 1 日 2016年2月 25 日, 全球40个国家和地区报告寨卡 病毒经蚊媒的本地传播, 主要集中在拉丁美洲和太 平洋岛国, 东南亚国家尚未报告持续性传播; 传播范
围有扩大趋势 (http://www.who.int/emergencies/zikavirus/situation-report-26-02-2016.pdf?ua=1). 埃 及伊 蚊可以有效传播寨卡病毒, 白纹伊蚊也可能有效传 播该病毒 ${ }^{[3]}$. 埃及伊蚊存在于我国海南省、广东省雷 州半岛、云南省的西双版纳州、德宏州及临沧市等地 区. 而白纹伊蚊则分布于北至沈阳、大连，西至陇县 和宝鸡, 西南至西藏墨脱一线及其东南侧的大部分 地区.

我国全年均可发生登革热输人性病例, 近年来, 来自东南亚国家的输人性病例占 $83 \%$, 而来自美洲 的输人性病例不到 $1 \%$. 输人性登革热造成本地传播 主要发生在6 8月, 但少数也可早至 2 月份. 近 20 年

引用格式: 涂文校, 马涛, 李昱, 等. 2016 年我国内地寨卡病毒的输人和传播风险评估. 科学通报, 2016, 61: 1344-1353

Tu W X, Ma T, Li Y, et al. Risk assessment on importation and autochthonous transmission of Zika virus disease in the mainland of China, 2016 (in Chinese). Chin Sci Bull, 2016, 61: 1344-1353, doi: 10.1360/N972016-00343 
来，除广东、云南可以发生持续半年以上、报告病例 数千乃至数万的登革热本地传播以外, 其他地区的 登革热本地传播主要表现为局部暴发, 规模从数例 到数百例不等, 通常 2 个月内疫情得到控制, 主要发 生在福建、广西和浙江等地区. 2013年9月河南省许昌 市曾发生登革热本地传播, 是我国发生位置最北的 一次登革热本地传播疫情.

2014 年我国公民出境旅游达 1.07 亿人次, 其中亚 洲占比达到 65.4\%, 美洲占 $9.0 \%$ (以北美为主)(http:// www.ctaweb.org/html/2015-10/2015-10-19-9-53-80124 .html). 2014年9月 2015年 8 月, 我国赴巴西旅游人数 约 8.4 万人 ${ }^{[4]} .2015$ 年, 除美国、加拿大和墨西哥以外, 美洲其他国家来华人数约为 28 万人; 而菲律宾、泰 国、新加坡、印尼、马来西亚这5个东南亚国家累计 来华人数高达 417 万(http://www.cnta.gov.cn/zwgk/lysj/ 201601/t20160118_758409.shtml), 即我国与拉丁美 洲人员往来规模远低于东南亚水平. 2016年 2 月, 我 国内地共发现10例输人性显性感染的寨卡病毒病确 诊病例, 尚无本地感染病例报告. 为明确2016年我国 内地不同地区在不同时期面临的寨卡病毒输人和本 地传播风险, 科学指导各地开展有针对性的防控和 应急准备工作, 特开展本次风险评估.

\section{1 方法与数据}

\section{1 病毒输入的风险分析}

传染病的输人病例数 $(C)$ 取决于我国与疫区的往 来人数 $(N)$, 旅行者在疫区的感染概率 $(I)$, 即: $C=$ $N \times I$. 在难以精确获取我国与寨卡病毒病疫区往来人 员数量和旅行者在当地感染概率的情况下, 可利用 近年来我国登革热输人性病例粗略推测寨卡病毒病 可能发生的输人病例数.

2016年2月, 我国内地发现输人性登革热病例 45 例 $\left(C_{\text {Denv }}\right)$, 寨卡病毒病 10 例 $\left(C_{\text {Zikv }}\right)$; 输人寨卡病毒病 与登革热的比例 $\left(P r o=C_{\mathrm{Zikv}} / C_{\mathrm{Denv}}\right)$ 为 $0.22(95 \%$ 置信区 间为 $0.10 \sim 0.31)$. 2016年1 2月, 东南亚、太平洋岛国 和南美等主要国家登革热疫情与往年同期相似或更 低 (http://www.wpro.who.int/emerging_diseases/DengueSituationUpdates/en/, http://portalsaude.saude.gov.br/index. php/situacao-epidemiologica-dados-dengue); 期间 我 国内地报告输人性登革热73例, 而2011 2015年每年 的1 2月平均报告输人登革热17例, 提示近期我国内
地登革热的监测发现灵敏度比往年同期水平高, 其 校正系数 $(S)$ 为4.29 (95\%置信区间为3.03 7.36). 如果 2016年全球寨卡病毒流行的时空变化与既往全球登 革热类似，则可根据2011 2015年我国内地每月平均 输人的登革热病例数, 乘以Pro和 $S$, 推测2016年不同 月份可能发生的寨卡病毒病输人病例数. 如果 2016 年寨卡病毒仍主要在美洲和太平洋岛国流行, 而东 南亚地区不发生较大规模的本地传播, 则根据 2014 2015年巴西登革热不同月份流行强度推测2016 年不同月份寨卡病毒可能的流行强度, 再用 $20 \%$ 输 人登革热来自东南亚以外地区的比例校正不同月份 可能输人我国内地的寨卡病毒病的病例数.

另外, 从疾病传播规律和我国现有相关政策角 度, 定性分析寨卡病毒经血液、血制品、组织和器官、 伊蚊成蚊和卵输人我国内地的风险.

\section{2 本地传播的风险分析}

参考登革热传播规律, 寨卡病毒要发生本地传 播, 首要的条件是在病毒输人时当地伊蚊密度要足 够; 其次是有充足数量的易感人群. 我国既往无寨卡 病毒流行, 人群普遍易感, 因此最主要是人群密度要 足够大, 如登革热在人口密度 $>3000$ 人/平方千米容 易发生本地传播 ${ }^{[5]}$. 根据专家的经验, 对不同指标赋 予不同的权重.

不同地区是否存在伊蚊、不同月份伊蚊密度相关 指标一一布雷图指数 $(B I)$, 参考既往我国内地蚊媒监 测和边界调查数据; 如果某个地区在某些时间段无 相应数据, 则用与其相邻近的地区、类似气象条件的 地区监测结果代替. 人口密度指标则用各省的城镇 化比例代替 (http://data.stats.gov.cn/search.htm?s=人 口), 病毒输人可能性用2011 2015年不同地区每月 平均登革热输人病例数来代替.

本地传播发生后的严重程度, 则根据我国内地历 史上登革热传播的情形, 可划分为 3 个等级: 发生后很 快被控制、局部范围流行一段时间和大规模流行(表1).

风险分析过程按照谨慎预防原则, 重要参数将 会更加偏向采用上限值来估计我国内地可能面临的 风险. 参照WHO风险评估指南中边界模糊的风险矩 阵组合发生可能性和后果, 形成风险等级 (http:// www.who.int/csr/resources/publications/HSE_GAR_AR O_2012_1/en/). 根据我国内地伊蚊的季节消长规律以 及登革热本地传播的时间分布特点, 按照 $3 \sim 5,6 \sim 10$ 


\section{表 1 寨卡病毒输入后本地传播的评估指标}

Tabel 1 Risk indicators for autochthonous transmission of Zika virus

\begin{tabular}{|c|c|c|c|}
\hline 评估指标 & & 权重 & 赋值条件参考 \\
\hline \multirow[t]{14}{*}{ 发生可能性 } & 蚊媒条件 $\left(A_{1}\right)$ & 3 & 无伊蚊分布, $A_{1}=0$ \\
\hline & & & $B I \leqslant 5, A_{1}=0.05$ \\
\hline & & & $5<B I \leqslant 20, A_{1}=1$ \\
\hline & & & $B I>20, A_{1}=2$ \\
\hline & 人口密度 $\left(A_{2}\right)$ & 1 & 城镇化率 $\leqslant 56.1 \%, A_{2}=1$ \\
\hline & & & 城镇化率> $>56.1 \%, A_{2}=2$ \\
\hline & 病毒输人 $\left(A_{3}\right)$ & 0.5 & 近 5 年月平均登革热输人病例数 $<1, A_{3}=1$ \\
\hline & & & 近 5 年月平均登革热输人病例数 $\geqslant 1, A_{3}=2$ \\
\hline & 发生可能性综合指标 $\left(A_{4}\right)$ & & $A_{4}=\left(A_{1} \times 3\right) \times\left(A_{2} \times 1\right) \times\left(A_{3} \times 0.5\right)$ \\
\hline & & & $A_{4}=12$, 可能性高 \\
\hline & & & $A_{4}=6$ 或 3, 可能性中等 \\
\hline & & & $A_{4}=1.5$, 可能性低 \\
\hline & & & $0<A_{4}<1.5$, 可能性极低 \\
\hline & & & $A_{4}=0$, 无可能 \\
\hline \multirow[t]{3}{*}{ 后果严重性 } & 低 & & 发生后很快被控制 (如: 报告病例数 $<100$ 例, 或持续时间 2 个月内) \\
\hline & 中 & & $\begin{array}{l}\text { 局部范围流行一段 时间 (如：报告病例数 } \\
100 \sim 10000, \text { 或持续时间3 6个月) }\end{array}$ \\
\hline & 高 & & 大规模流行(如报告病例数>10000, 或持续时间>6个月) \\
\hline
\end{tabular}

和11 12月3个时间段, 对我国内地2016年不同地区 的寨卡病毒病本地传播风险进行评估.

\section{2 结果}

\section{1 寨卡病毒输入风险}

(i ) 输人病例数规模估计. 假设我国内地的登 革热和寨卡病毒病监测系统灵敏度保持2016年1 2月
同等水平, 如果2016年寨卡病毒仍主要在美洲和太 平洋岛国流行、东南亚不流行，则预测2016年3 12月 可能发现的输人性寨卡病毒病为 25 例( $95 \%$ 置信区间 为8 68); 如果东南亚也出现类似往年登革热一样的 流行规模，则预测2016年3 12月我国内地可能发现 的输人性寨卡病毒病为 329 例 (95\%置信区间为 106 876)，见表2.

（ii）经伊蚊成蚊或虫卵输人。既往研究表明,

表 22016 年 3 12 月我国内地可能发生输入性寨卡病毒病例数估计

Table 2 The estimation imported cases of Zika virus disease in the mainland of China from March to December, 2016

\begin{tabular}{|c|c|c|c|c|c|c|}
\hline \multirow[t]{2}{*}{ 月份 } & \multirow{2}{*}{$\begin{array}{c}2011 \sim 2015 \text { 年 } \\
\text { 我国内地输人登革 } \\
\text { 热病例数均值 } \\
\end{array}$} & \multirow{2}{*}{$\begin{array}{c}\text { 巴西登革热 } \\
\text { 不同月份的流行 } \\
\text { 强度系数 }^{\text {a) }}\end{array}$} & \multicolumn{2}{|c|}{$\begin{array}{l}\text { 寨卡病毒在东南亚 } \\
\text { 未出现大规模流行 }\end{array}$} & \multicolumn{2}{|c|}{$\begin{array}{l}\text { 全球寨卡病毒病疫情 } \\
\text { 类似登革热时空变化 }\end{array}$} \\
\hline & & & 均值 & $(95 \% \mathrm{CI})$ & 均值 & $(95 \% \mathrm{CI})$ \\
\hline 2016年3月 & 11 & 0.1639 & 3 & $(1,7)$ & 10 & $(3,28)$ \\
\hline 2016年4月 & 12 & 0.2459 & 5 & $(1,12)$ & 11 & $(4,30)$ \\
\hline 2016年5月 & 17 & 0.1639 & 4 & $(1,11)$ & 16 & $(5,42)$ \\
\hline 2016年6月 & 18 & 0.0902 & 2 & $(1,7)$ & 17 & $(5,45)$ \\
\hline 2016年7月 & 33 & 0.0410 & 2 & $(1,6)$ & 31 & $(10,83)$ \\
\hline 2016年8月 & 47 & 0.0287 & 2 & $(1,5)$ & 44 & $(14,118)$ \\
\hline 2016年9月 & 65 & 0.0246 & 2 & $(1,7)$ & 62 & $(20,165)$ \\
\hline 2016年10月 & 97 & 0.0205 & 3 & $(1,8)$ & 93 & $(30,246)$ \\
\hline 2016年11月 & 32 & 0.0246 & 1 & $(0,3)$ & 30 & $(10,80)$ \\
\hline 2016年12月 & 15 & 0.0328 & 1 & $(0,2)$ & 15 & $(5,39)$ \\
\hline 2016年3 12月 & 346 & & 25 & $(8,68)$ & 329 & $(106,876)$ \\
\hline
\end{tabular}

a) 该流行强度系数为2014 2015年巴西不同月份登革热病例数占全年病例数的比例 
白纹伊蚊的虫卵可以经废弃轮胎运输到达目的地后 再孵化为成蚊 ${ }^{[6]}$. 自然界中登革热病毒可以在伊蚊中 经卵垂直传播 ${ }^{[7]}$. 因此理论上可能发生寨卡病毒经货 物贸易将染毒的伊蚊成蚊或其虫卵从疫情流行区输 人我国. 我国要求人境货物需要提供有效的灭蚊证 书, 彻底杀灭船舶、航空器上的埃及伊蚊及其虫卵, 在没有完成灭蚊以前限制该船与陆地和其他船舶的 距离不少于 $400 \mathrm{~m}$ (伊蚊飞行距离通常 $200 \mathrm{~m}$ 以内); 在 $400 \mathrm{~m}$ 防护带内开展媒介生物监测, 超出标准的通报 地方政府和卫生管理部门进行处置 ${ }^{[8]}$. 另外, 人境口 岸通常较为远离居民区, 人口密度小, 也无众多的非 人灵长类动物, 难以形成有效传播.

(iii) 经血液、血制品或人体组织输人. 我国规定 人境人体血液、血浆、组织、器官、细胞、骨髓等, 应 当提供卫生主管部门的批准文件和医疗机构出具的供 体健康证明和相关检验报告 (http://www.aqsiq.gov. cn/xxgk_13386/jlgg_12538/zj1/2015/201502/t20150203 _431143.htm). 目前我国禁止除人血白蛋白以外的血液 制品进口(http://www.sda.gov.cn/WS01/CL0051/141420. $\mathrm{html}$ ). 以人源血浆为原料提取白蛋白的生产工艺 ${ }^{[9]}$ 在理论上是可以灭活寨卡病毒. 因此可以认为当 前寨卡病毒不会经血液、血制品或人体组织输人我国 内地.

\section{2 输入寨卡病毒后的本地传播风险}

（i ）“人-伊蚊-人”的持续传播. 综合各省区本 地传播发生的可能性和后果严重性, 对各地不同时 期输人寨卡病毒后的本地传播风险进行了评价, 结 果见表3 5和图 1. 其中广西和浙江的风险等级根据 专家讨论意见进行调整. 广西调整风险等级理由: 3 5月部分地区气温回升和降水条件适宜, 蚊媒密度 水平较高. 浙江调整风险等级理由: 国内外旅游人数 多, 2015年自巴西人境浙江旅游人次达 4 万 (http:// www.tourzj.gov.cn/ShowNew.aspx?id=43164)(全国约 8.4 万), 且已经发生输人性病例, 部分区域的蚊媒密 度水平有可能会达到本地传播水平.

(ii) 性传播和输血造成续发感染病例. 目前已 有若干起寨卡病毒病男性病例经性传播将病毒传染 给其性伴侣, 但只产生 1 代病例, 不形成持续传播 ${ }^{[10]}$. 理论上病例在病毒血症期间献血可能造成输血者感 染; $\mathrm{WHO}$ 等组织和机构已提出对可能暴露于寨卡病 毒人员自最后一次可能的暴露起间隔 $28 \mathrm{~d}$ 以上方能
献血的管理建议. 因此这两类传播途径不会造成本 地持续性传播. 但需要予以关注, 因为性传播可能造 成孕妇感染, 进而可能导致胎儿小头畸形.

\section{3 讨论和结论}

我国内地与其他国家的人员往来频繁 ${ }^{[11 ~ 13]}$, 在 全球寨卡病毒病疫情未得到有效控制的情况下, 我 国内地将继续发生输人性病例. 2014年寨卡病毒输人 巴西, 但到2015年才形成较大规模流行(http://portalsaude.saude.gov.br/index.php/situacao-epidemiologicadados-dengue), 提示寨卡病毒输人一个地区到广泛流 行, 可能需要较长的一段时间. 据此预测2016年东南 亚大规模流行的可能性较小. 因此我国内地病例输 人的主要来源仍将是美洲和太平洋岛国，即2016年 $3 \sim 12$ 月继续发现的输入病例数约为 25 例 $(95 \%$ 置信区 间为 8 68)的可能性较大. 本文当前估计 2016年可能 发生的输人性寨卡病毒病病例应为高估值, 主要理 由: 预计2016年实际发生的寨卡病毒和登革热等蚊 媒传染病在全球的流行强度会比2011 2015年水平更 低. 因为2016年以前WHO未将登革热宣布为国际关 注的突发公共卫生事件, 而2016年2月1日WHO将巴 西小头畸形聚集性病例宣布为国际关注的突发公共 卫生事件, 认为其可能与寨卡病毒感染相关, 号召全 球做好蚊媒控制和个人防蚊为主的防控措施, 包括 巴西在内的多国均已经加强防控, 蚊媒控制措施力 度明显加大.

我国内地存在本地传播的风险, 发生可能性较高 的时间段在6 10月. 2016年3 5月, 广东、云南、海南、 福建和广西可能发生本地传播; 其余地区发生本地传 播的风险较低. 2016年6 10月, 广东、云南、海南、福 建、广西和浙江发生本地传播的风险增大, 并可能发生 聚集性疫情, 如果蚊媒控制不力, 还有可能发生较大 规模流行; 其余有白纹伊蚊的地区均有可能出现本地 传播. 2016年11 12月, 广东、云南、海南、福建、广西 和浙江发生本地传播风险较低; 其他地区发生本地感 染病例的风险极低. 内蒙古、吉林、黑龙江、青海、宁 夏、新疆等省区和辽宁、陕西、甘肃、西藏无伊蚊分 布地区，全年均不会发生本地传播. 鉴于我国内地今 年蚊媒监测和控制工作部署早、力度大(http://www. nhfpc.gov.cn/jkj/s5898/201602/f9e442e723494cd5bc22989cb 57f68af.shtml), 可以预期2016年即使发生寨卡病毒 病本地病例, 发生大范围、高强度传播的可能性不大. 
表 32016 年 3 5 月我国内地不同地区寨卡病毒本地传播风险

Table 3 The risk level of Zika virus autochthonous transmission by region of the mainland of China from March to May, 2016

\begin{tabular}{|c|c|c|c|c|c|c|c|}
\hline \multirow[b]{2}{*}{ 地区 } & \multicolumn{5}{|c|}{ 本地传播的可能性 } & \multirow{2}{*}{$\begin{array}{c}\text { 后果 } \\
\text { 严重性 }\end{array}$} & \multirow{2}{*}{$\begin{array}{l}\text { 最终 } \\
\text { 风险 }\end{array}$} \\
\hline & $\begin{array}{c}\text { 蚊媒密度 } \\
\left(A_{1}\right)\end{array}$ & $\begin{array}{c}\text { 人口密度 } \\
\left(A_{2}\right)\end{array}$ & $\begin{array}{c}\text { 病毒输人 } \\
\left(A_{3}\right)\end{array}$ & $\begin{array}{l}\text { 综合 } \\
\left(A_{4}\right)\end{array}$ & 可能性 & & \\
\hline 广东 & 1 & 2 & 2 & 6 & 中等 & 中等 & 中等 \\
\hline 福建 & 1 & 2 & 2 & 6 & 中等 & 低 & 中等 \\
\hline 海南 & 2 & 1 & 1 & 3 & 中等 & 低 & 中等 \\
\hline 云南 & 1 & 1 & 1 & 1.5 & 低 & 中等 & 中等 \\
\hline 广西a) & 1 & 1 & 1 & 1.5 & 低 & 低 & 低(调为中等) \\
\hline 江西 & 1 & 1 & 1 & 1.5 & 低 & 低 & 低 \\
\hline 湖南 & 1 & 1 & 1 & 1.5 & 低 & 低 & 低 \\
\hline 贵州 & 1 & 1 & 1 & 1.5 & 低 & 低 & 低 \\
\hline 浙江 ${ }^{\text {b) }}$ & 0.05 & 2 & 2 & 0.3 & 极低 & 低 & 极低(调为中等) \\
\hline 北京 & 0.05 & 2 & 1 & 0.15 & 极低 & 低 & 极低 \\
\hline 天津 & 0.05 & 2 & 1 & 0.15 & 极低 & 低 & 极低 \\
\hline 上海 & 0.05 & 2 & 1 & 0.15 & 极低 & 低 & 极低 \\
\hline 江苏 & 0.05 & 2 & 1 & 0.15 & 极低 & 低 & 极低 \\
\hline 重庆 & 0.05 & 2 & 1 & 0.15 & 极低 & 低 & 极低 \\
\hline 河北 & 0.05 & 1 & 1 & 0.075 & 极低 & 低 & 极低 \\
\hline 山西 & 0.05 & 1 & 1 & 0.075 & 极低 & 低 & 极低 \\
\hline 安徽 & 0.05 & 1 & 1 & 0.075 & 极低 & 低 & 极低 \\
\hline 山东 & 0.05 & 1 & 1 & 0.075 & 极低 & 低 & 极低 \\
\hline 河南 & 0.05 & 1 & 1 & 0.075 & 极低 & 低 & 极低 \\
\hline 湖北 & 0.05 & 1 & 1 & 0.075 & 极低 & 低 & 极低 \\
\hline 四川 & 0.05 & 1 & 1 & 0.075 & 极低 & 低 & 极低 \\
\hline 辽宁c) & 0.05 & 2 & 1 & 0.15 & 极低 & 低 & 极低 \\
\hline 陕西 ${ }^{c)}$ & 0.05 & 1 & 1 & 0.075 & 极低 & 低 & 极低 \\
\hline 西藏() & 0 & 1 & 1 & 0 & 零 & 低 & 无风险 \\
\hline 内蒙古 & 0 & 2 & 1 & 0 & 零 & 低 & 无风险 \\
\hline 吉林 & 0 & 1 & 1 & 0 & 零 & 低 & 无风险 \\
\hline 黑龙江 & 0 & 2 & 1 & 0 & 零 & 低 & 无风险 \\
\hline 甘肃 & 0 & 1 & 1 & 0 & 零 & 低 & 无风险 \\
\hline 青海 & 0 & 1 & 1 & 0 & 零 & 低 & 无风险 \\
\hline 宁夏 & 0 & 1 & 1 & 0 & 零 & 低 & 无风险 \\
\hline 新疆 & 0 & 1 & 1 & 0 & 零 & 低 & 无风险 \\
\hline
\end{tabular}

a) 广西调整风险等级理由: $3 \sim 5$ 月部分地区气温回升和降水条件适宜，蚊媒密度水平较高; b) 浙江调整风险等级理由：国内外旅 游人数多, 2015 年自巴西人境浙江旅游人次达 4 万(全国约 8.4 万), 且已经发生输人性病例, 部分区域的蚊媒密度水平有可能会达到本地 传播水平；c）辽宁、陕西和西藏大部分无伊蚊分布地区，无寨卡病毒本地传播风险；表中粗体说明风险等级有调整 
表 42016 年 6 10 月我国内地不同地区寨卡病毒本地传播风险

Table 4 The risk level of Zika virus autochthonous transmission by region of the mainland of China from June to October, 2016

\begin{tabular}{|c|c|c|c|c|c|c|c|}
\hline \multirow{2}{*}{ 地区 } & \multicolumn{5}{|c|}{ 本地传播的可能性 } & \multirow{2}{*}{$\begin{array}{c}\text { 后果 } \\
\text { 严重性 }\end{array}$} & \multirow{2}{*}{$\begin{array}{l}\text { 最终 } \\
\text { 风险 }\end{array}$} \\
\hline & $\begin{array}{c}\text { 蚊媒密度 } \\
\left(A_{1}\right)\end{array}$ & $\begin{array}{c}\text { 人口密度 } \\
\left(A_{2}\right)\end{array}$ & $\begin{array}{c}\text { 病毒输人 } \\
\left(A_{3}\right)\end{array}$ & $\begin{array}{l}\text { 综合 } \\
\left(A_{4}\right)\end{array}$ & 可能性 & & \\
\hline 广东 & 2 & 2 & 2 & 12 & 高 & 中等 & 高 \\
\hline 福建 & 2 & 2 & 2 & 12 & 高 & 中等 & 高 \\
\hline 云南 & 2 & 2 & 2 & 12 & 高 & 中等 & 高 \\
\hline 广西 & 2 & 2 & 1 & 6 & 中等 & 中等 & 高 \\
\hline 海南 & 2 & 1 & 1 & 3 & 中等 & 中等 & 高 \\
\hline 浙江 ${ }^{\text {a) }}$ & 1 & 2 & 2 & 6 & 中等 & 低 & 中等(调为高) \\
\hline 北京 & 1 & 2 & 2 & 6 & 中等 & 低 & 中等 \\
\hline 湖北 & 1 & 2 & 2 & 6 & 中等 & 低 & 中等 \\
\hline 湖南 & 1 & 2 & 2 & 6 & 中等 & 低 & 中等 \\
\hline 重庆 & 1 & 2 & 2 & 6 & 中等 & 低 & 中等 \\
\hline 四川 & 1 & 2 & 2 & 6 & 中等 & 低 & 中等 \\
\hline 江苏 & 1 & 1 & 2 & 3 & 中等 & 低 & 中等 \\
\hline 江西 & 1 & 1 & 2 & 3 & 中等 & 低 & 中等 \\
\hline 山东 & 1 & 2 & 1 & 3 & 中等 & 低 & 中等 \\
\hline 天津 & 1 & 1 & 1 & 1.5 & 低 & 低 & 低 \\
\hline 河北 & 1 & 1 & 1 & 1.5 & 低 & 低 & 低 \\
\hline 山西 & 1 & 1 & 1 & 1.5 & 低 & 低 & 低 \\
\hline 上海 & 1 & 1 & 1 & 1.5 & 低 & 低 & 低 \\
\hline 安徽 & 1 & 1 & 1 & 1.5 & 低 & 低 & 低 \\
\hline 河南 & 1 & 1 & 1 & 1.5 & 低 & 低 & 低 \\
\hline 贵州 & 1 & 1 & 1 & 1.5 & 低 & 低 & 低 \\
\hline 陕西b) & 1 & 1 & 1 & 1.5 & 低 & 低 & 低 \\
\hline 辽宁 ${ }^{b)}$ & 1 & 1 & 1 & 1.5 & 低 & 低 & 低 \\
\hline 西藏b) & 0 & 1 & 1 & 0 & 零 & 低 & 零 \\
\hline 甘肃) & 0 & 1 & 1 & 0 & 零 & 低 & 零 \\
\hline 内蒙古 & 0 & 1 & 1 & 0 & 零 & 低 & 零 \\
\hline 吉林 & 0 & 1 & 1 & 0 & 零 & 低 & 零 \\
\hline 黑龙江 & 0 & 1 & 1 & 0 & 零 & 低 & 零 \\
\hline 青海 & 0 & 1 & 1 & 0 & 零 & 低 & 零 \\
\hline 宁夏 & 0 & 1 & 1 & 0 & 零 & 低 & 零 \\
\hline 新疆 & 0 & 1 & 1 & 0 & 零 & 低 & 零 \\
\hline
\end{tabular}

a) 浙江风险等级调整理由同表3; b) 辽宁、陕西、甘肃、西藏大部分无伊蚊分布地区，无寨卡病毒本地传播风险; 表中粗体说明 风险等级有调整 
表 52016 年 11 12 月我国内地不同地区寨卡病毒本地传播风险

Table 5 The risk level of Zika virus autochthonous transmission by region of the mainland of China from November to December, 2016

\begin{tabular}{|c|c|c|c|c|c|c|c|}
\hline \multirow[b]{2}{*}{ 地区 } & \multicolumn{5}{|c|}{ 本地传播的可能性 } & \multirow{2}{*}{$\begin{array}{c}\text { 后果 } \\
\text { 严重性 }\end{array}$} & \multirow{2}{*}{$\begin{array}{l}\text { 最终 } \\
\text { 风险 }\end{array}$} \\
\hline & $\begin{array}{c}\text { 蚊媒密度 } \\
\left(A_{1}\right)\end{array}$ & $\begin{array}{c}\text { 人口密度 } \\
\left(A_{2}\right)\end{array}$ & $\begin{array}{c}\text { 病毒输人 } \\
\left(A_{3}\right)\end{array}$ & $\begin{array}{l}\text { 综合 } \\
\left(A_{4}\right) \\
\end{array}$ & 可能性 & & \\
\hline 广东 & 1 & 2 & 2 & 6 & 中等 & 低 & 中等 \\
\hline 福建 & 1 & 2 & 1 & 3 & 中等 & 低 & 中等 \\
\hline 海南 & 2 & 1 & 1 & 3 & 中等 & 中等 & 中等 \\
\hline 云南 & 1 & 1 & 2 & 3 & 中等 & 低 & 中等 \\
\hline 广西a) & 1 & 1 & 1 & 1.5 & 低 & 低 & 低(调为中等) \\
\hline 江西 & 1 & 1 & 1 & 1.5 & 低 & 低 & 低 \\
\hline 贵州 & 1 & 1 & 1 & 1.5 & 低 & 低 & 低 \\
\hline 浙江 ${ }^{\text {a) }}$ & 0.05 & 2 & 1 & 0.15 & 极低 & 低 & 极低(调为中等) \\
\hline 北京 & 0.05 & 2 & 1 & 0.15 & 极低 & 低 & 极低 \\
\hline 天津 & 0.05 & 2 & 1 & 0.15 & 极低 & 低 & 极低 \\
\hline 辽宁 & 0.05 & 2 & 1 & 0.15 & 极低 & 低 & 极低 \\
\hline 上海 & 0.05 & 2 & 1 & 0.15 & 极低 & 低 & 极低 \\
\hline 江苏 & 0.05 & 2 & 1 & 0.15 & 极低 & 低 & 极低 \\
\hline 重庆 & 0.05 & 2 & 1 & 0.15 & 极低 & 低 & 极低 \\
\hline 河北 & 0.05 & 1 & 1 & 0.075 & 极低 & 低 & 极低 \\
\hline 山西 & 0.05 & 1 & 1 & 0.075 & 极低 & 低 & 极低 \\
\hline 安徽 & 0.05 & 1 & 1 & 0.075 & 极低 & 低 & 极低 \\
\hline 山东 & 0.05 & 1 & 1 & 0.075 & 极低 & 低 & 极低 \\
\hline 河南 & 0.05 & 1 & 1 & 0.075 & 极低 & 低 & 极低 \\
\hline 湖北 & 0.05 & 1 & 1 & 0.075 & 极低 & 低 & 极低 \\
\hline 湖南 & 0.05 & 1 & 1 & 0.075 & 极低 & 低 & 极低 \\
\hline 四川 & 0.05 & 1 & 1 & 0.075 & 极低 & 低 & 极低 \\
\hline 陕西 & 0.05 & 1 & 1 & 0.075 & 极低 & 低 & 极低 \\
\hline 内蒙古 & 0 & 2 & 1 & 0 & 零 & 低 & 无风险 \\
\hline 吉林 & 0 & 1 & 1 & 0 & 零 & 低 & 无风险 \\
\hline 黑龙江 & 0 & 2 & 1 & 0 & 零 & 低 & 无风险 \\
\hline 西藏 & 0 & 1 & 1 & 0 & 零 & 低 & 无风险 \\
\hline 甘肃 & 0 & 1 & 1 & 0 & 零 & 低 & 无风险 \\
\hline 青海 & 0 & 1 & 1 & 0 & 零 & 低 & 无风险 \\
\hline 宁夏 & 0 & 1 & 1 & 0 & 零 & 低 & 无风险 \\
\hline 新疆 & 0 & 1 & 1 & 0 & 零 & 低 & 无风险 \\
\hline
\end{tabular}

a) 浙江和广西的风险等级调整理由同表3; 表中粗体说明风险等级有调整

本文在风险评估过程中, 仍然存在以下方面的不 确定性: (1) 白纹伊蚊导致寨卡病毒在人间流行传播效 率尚待现场实验的证实, 如果白纹伊蚊实际传播寨卡 病毒的能力远低于埃及伊蚊, 则我国内地只有少数省 份可能发生本地传播; (2) 2016年东南亚寨卡病毒的疫 情是否能够较大规模传播, 现在难以判断, 一旦其大规 模流行, 将会给我国内地带来较大的输人压力; (3) 难
以获得精确的我国内地与各疫区国家往来人员数量、旅 行目的地的疫情流行状况、旅行者的居住条件、居住 时间等数据, 因此输人性病例数的规模无法精确估计.

风险管理建议: (1) 有本地传播风险的省区需加 强蚊媒监测, 在没有病例发生时, 要将布雷图指数控 制在20以下; (2) 做好输人性病例的监测, 有本地传 播风险的省区发现输人病例后要在疫点周边地区预 

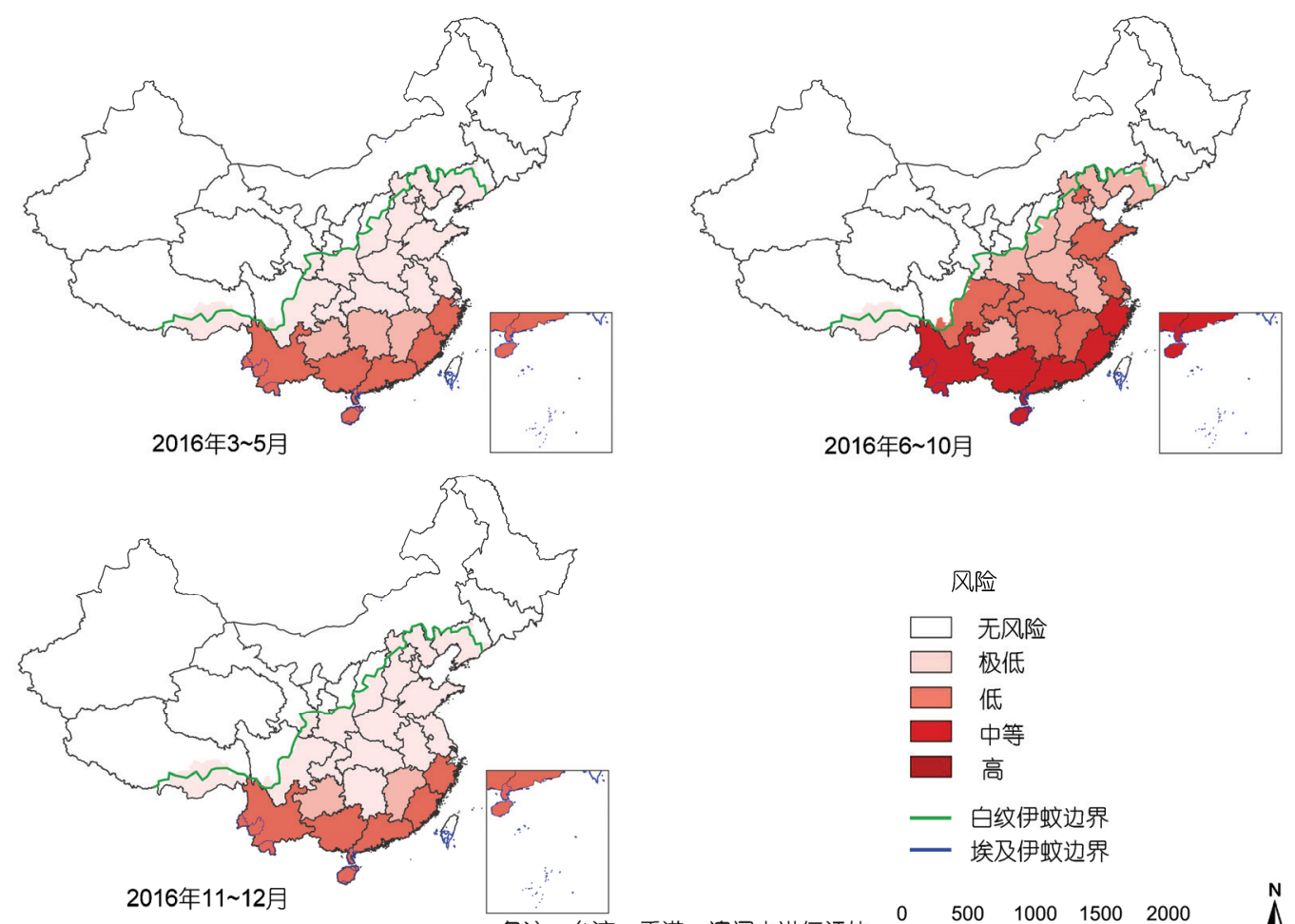

备注：台湾、香港、澳门未进行评估

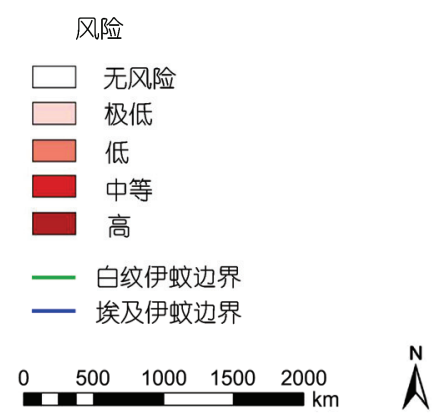

图 1 (网络版彩色) 2016 年不同地区和时期寨卡病毒在我国本地传播的风险

Figure 1 (Color online) The risk maps of Zika virus autochthonous transmission in the mainland of China by different periods of 2016

防性灭蚊并将布雷图指数控制在 5 以下; (3) 做好赴 疫区旅游人员和在疫区的留学、务工和商务人员的健 康提示，提高个人防蚊能力; 孕妇及准备怀孕的女性
应尽量避免前往疫区旅行；(4) 跟踪国际寨卡病毒病 疫情进展以及寨卡病毒感染与小头畸形等神经系统 疾病的研究进展, 动态开展风险评估.

\section{参考文献}

1 Meaney-Delman D, Hills S L, Williams C, et al. Zika virus infection among U.S. Pregnant travelers-August 2015-February 2016. MMWR Morb Mortal Wkly Rep, 2016, 65: 211-214

2 Cao-Lormeau V, Blake A, Mons S, et al. Guillain-barré syndrome outbreak associated with zika virus infection in French Polynesia: A case-control study. Lancet, 2016, doi: http://dx.doi.org/10.1016/S0140-6736(16)00562-6

3 Wong P S, Li M Z, Chong C S, et al. Aedes (stegomyia) albopictus (skuse): A potential vector of zika virus in Singapore. PLoS Negl Trop Dis, 2013, 7: e2348

4 Bogoch I I, Brady O J, Kraemer M U, et al. Anticipating the international spread of zika virus from Brazil. Lancet, 2016, 387: 335-336

5 Schmidt W P, Suzuki M, Thiem V D, et al. Population density, water supply, and the risk of dengue fever in Vietnam: Cohort study and spatial analysis. PLoS Med, 2011, 8: e1001082

6 Hanson S M, Lampman R L, Novak R J, et al. Aedes albopictus and ae. Triseriatus eggs survive waste tire processing. J Am Mosq Control Assoc, 1996, 12: 728-729

7 Cruz L C, Serra O P, Leal-Santos F A, et al. Natural transovarial transmission of dengue virus 4 in aedes aegypti from Cuiaba, State of Mato Grosso, Brazil. Rev Soc Bras Med Trop, 2015, 48: 18-25 
8 General Administration of Quality Supervision, Inspection and Quarantine of the People's Republic of China. SN/T 3159 General Requirements for the International Sanitary Port (in Chinese). Beijing: Standards Press of China, 2012 [中华人民共和国国家质量检验检 疫监督总局. SN/T 3159 国际卫生港口通用要求. 北京：中国标准出版社, 2012]

9 Wang M Y, Wang F, Zang H C, et al. Research progress on production and application of human albumin (in Chinese). J Pharmaceut Res, 2014, 10: 600-602 [王鸣宇, 王斐, 藏恒昌, 等. 人血白蛋白生产及其应用研究进展. 药学研究, 2014, 10: 600-602]

10 Hills S L, Russell K, Hennessey M, et al. Transmission of zika virus through sexual contact with travelers to areas of ongoing transmission-continental united states. MMWR Morb Mortal Wkly Rep, 2016, doi: http://dx.doi.org/10.15585/mmwr.mm6508e2er

11 Lai S J, Miniota J, Wang L P, et al. Assessing potential airlines and the risk of Ebolavirus importation from west African countries into China (in Chinese). Chin Sci Bull, 2014, 59: 3572-3580 [赖圣杰, Miniota J, 王丽萍, 等. 西非埃博拉病毒病传人中国的可能航线和 风险估计. 科学通报, 2014, 59: 3572-3580]

12 Geng M J, Khan K, Ren X, et al. Assessing the risk of MERS importation from South Korea into cities of China: A retrospective study (in Chinese). Chin Sci Bull, 2016, 61: 1016-1024 [耿梦杰, Khan K, 任翔, 等. 中东呼吸综合征疫情由韩国传人中国不同城市风险 的回顾性评估与探讨. 科学通报, 2016, 61: 1016-1024]

13 Li J, Xiong Y, Wu W, et al. Zika virus in a traveler returning to China from Caracas, Venezuela, February 2016. Emerg Infect Dis, 2016, doi: $10.3201 /$ eid2206.160273 


\title{
Risk assessment on importation and autochthonous transmission of Zika virus disease in the mainland of China, 2016
}

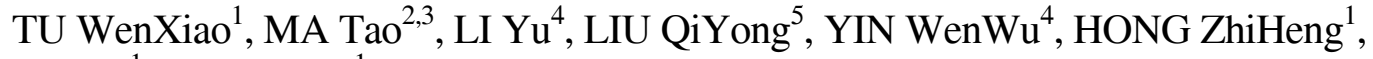 \\ LI Qun ${ }^{1} \&$ NI DaXin ${ }^{1}$ \\ ${ }^{1}$ Public Health Emergency Center, Chinese Center for Disease Control and Prevention, Beijing 102206, China; \\ ${ }^{2}$ Chinese Field Epidemiology Training Progam, Chinese Center for Disease Control and Prevention, Beijing 100050, China; \\ ${ }^{3}$ Nanjing Center for Disease Control and Prevention, Nanjing 210003, China; \\ ${ }^{4}$ Division of Infectious Disease Pevention and Control, Chinese Center for Disease Control and Prevention, Beijing 102206, China; \\ ${ }^{5}$ National Institute for Communicable Disease Control and Pevention, Chinese Center for Disease Control and Prevention, Beijing 102206, China
}

Word Health Organizaiton has declared the clusters of microcephaly cases and other neurological disorders constituted a Public Health Emergency of International Concern on 1 Feberuary 2016, and there is increasing evidence that they are causal related with Zika virus. Zika virus disease has been identified in 41 countires and areas since 2015, and it is spreading to the other parts of the world. There were 10 imported cases of Zika virus disease detected in the mainland of China from January to February 2016, without autochthonous transmission.

In order to identify the risk of importation and autochthonous transmission of Zika virus disease in the mainland of China from March to December, 2016, we conducted a qualitative and quantitative risk assessment. We assumed that the Zika virus might have the similar transmission pattern as dengue virus. The surveillance data of dengue fever in the mainland of China were analyzed for infering the importation and local transmission of Zika virus. Travelling between China and those areas with Zika virus autochthonous transmission was used to assess the risk of importation. Surveillance and border investigation information of Aedes aegypti and Aedes albopictus, and the urbanization rates of each provinces in 2015 were used to assess the risk of autochthonous transmission.

There would be more imported cases of Zika virus disease detected in the mainland of China, the total case number might be 8-68 from March to December 2016 if there was no big outbreak of Zika virus disease in Southeast Asia, and the total case number might be up to 106-876 if the epidemic situation of Zika virus disease was similar as dengue in Southeast Asia. The period at the highest risk for autochthonous transmission of Zika virus in the mainland of China would be between June and October; the regions at the highest risk of autochthonous transmission minght be Guangdong, Yunnan, Hainan, Fujian, Guangxi and Zhejiang; there was with some risk of autochthonous transmission for the other provinces with Aedes albopictus; and there is no risk of autochthonous transmission for the regions of Inner Mongolia, Jilin, Heilongjiang, Qinghai, Xinjiang, and those areas without Aedes albopictus in Liaoning, Shaanxi, Gansu and Tibet.

We suggest that all provinces should continue to monitor the possible imported cases of Zika virus disease; provinces at risk of of autochthonous transmission should strengthen the mosquito surveillance during the mosquito active seasons and control the vector density; travellers to areas with Zika virus outbreaks should be provided with up to date health information and pregnant women should avoid travelling to those areas; and dynamic risk assessment should be carried out according to the epidemic situation and research progress.

Zika virus disease, risk assessment, mosquito borne infectious diseases, imported case, autochthonous transmission

doi: 10.1360/N972016-00343 